\title{
Red Tomato Juice
}

National Cancer Institute

\section{Source}

National Cancer Institute. Red Tomato Juice. NCI Thesaurus. Code C116328.

Tomato juice derived from red tomatoes, with potential antioxidant and chemopreventive activities. Red tomato juice contains higher levels of the trans-isomer of lycopene (trans-LYC) compared to the cis-isomer (cis-LYC). Lycopene, a linear, unsaturated hydrocarbon carotenoid, is the major red pigment in certain fruits such as tomatoes, pink grapefruit, apricots, red oranges, watermelon, rosehips, and guava. As an antioxidant, lycopene scavenges free radicals which may both inhibit cellular oxidation and prevent free radical damage to cells. cis-LYC is better absorbed than its trans form. 